\title{
Suscetibilidade diferencial de espécies de braquiária ao herbicida glifosato
}

\author{
Alexandre Magno Brighenti(1), Fausto de Souza Sobrinho(1), Wadson Sebastião Duarte da Rocha(1), \\ Carlos Eugênio Martins ${ }^{(1)}$, Dalmir Demartini( ${ }^{(2)}$ e Thiago Rodrigues Costa ${ }^{(3)}$
}

\begin{abstract}
(1)Embrapa Gado de Leite, Rua Eugênio do Nascimento, №610, Bairro Dom Bosco, CEP $36038-330$ Juiz de Fora, MG. E-mail: brighent@cnpgl.embrapa.br, fausto@cnpgl.embrapa.br, wadson@cnpgl.embrapa.br, caeuma@cnpgl.embrapa.br(2)Faculdade de Itapiranga, Rua Carlos Kummer, s/nº, CEP 89896-000 Itapiranga, SC. E-mail: dalmirdemartini@gmail.com ${ }^{(3)}$ Centro de Ensino Superior de Juiz de Fora, Rua Luz Interior, no 345, CEP 36030-790 Juiz de Fora, MG. E-mail: thiagobioces@oi.com.br
\end{abstract}

Resumo - O objetivo deste trabalho foi avaliar a suscetibilidade diferencial de espécies de Urochloa ao herbicida glifosato. Dois experimentos foram implantados na Embrapa Gado de Leite, em Juiz de Fora, MG. O primeiro experimento foi realizado em vasos dispostos em bancadas, em ambiente aberto, e o segundo em campo. Em ambos os experimentos, adotou-se o delineamento experimental em blocos ao acaso, com parcelas subdivididas. Nas parcelas, foram semeadas três espécies de braquiária (U. brizantha, U. decumbens e U. ruziziensis) e, nas subparcelas, foram dispostas as doses do equivalente ácido do herbicida glifosato $\left(0,180,360,540,720,1.080,1.440 \mathrm{~g} \mathrm{ha}^{-1}\right)$. Há variabilidade entre as espécies avaliadas de Urochloa, quanto à suscetibilidade ao herbicida glifosato, e U. ruziziensis é a mais suscetível. O conhecimento da suscetibilidade diferencial entre as espécies de Urochloa avaliadas permite uma economia de 12 a 16\% na dose do herbicida glifosato.

Termos para indexação: Brachiaria, Urochloa, dessecação, forrageiras, integração lavoura-pecuária, plantio direto.

\section{Differential susceptibility of brachiaria species to glyphosate}

\begin{abstract}
The objective of this work was to evaluate the differential susceptibility of Urochloa species to glyphosate. Two experiments were carried out at Embrapa Gado de Leite, in Juiz de Fora, Minas Gerais state, Brazil. The first experiment was carried out in pots placed on benches in an open environment, and the second one in the field. A randomized block design arranged in split plot was used for both experiments. Three species of brachiaria ( $U$. brizantha, $U$. decumbens and $U$. ruziziensis) were sown in the plots, and the subplots consisted of the glyphosate acid equivalent doses $\left(0,180,360,540,720,1,080\right.$, and 1,440 $\left.\mathrm{g} \mathrm{ha}^{-1}\right)$. There is variability among the evaluated Urochloa species regarding glyphosate susceptibility, and U. ruziziensis is the most susceptible. The knowledge on the differential susceptibility among the evaluated Urochloa species allows for a saving from 12 to $16 \%$ herbicide glyphosate dose.
\end{abstract}

Index terms: Brachiaria, Urochloa, desiccation, forage grasses, crop-livestock integration, no-till.

\section{Introdução}

A cobertura vegetal da superfície do solo, antes da semeadura das culturas, é fundamental para a implantação do sistema plantio direto (Ruedell, 1995). Assim, o emprego de espécies com elevada produtividade de fitomassa é um dos fatores para que se alcance sucesso nesse sistema.

Em regiões como a do Cerrado brasileiro, onde o inverno é seco, com fotoperíodo curto, há certa dificuldade em se produzir grande quantidade de palha. Além disso, o início das chuvas na região causa rápida decomposição da palha, em razão do aumento da umidade e da temperatura. Trabalhos de pesquisa têm demonstrado que a maior limitação para a manutenção da palha sobre o solo, em regiões de clima tropical, é a rapidez com que a massa vegetal se decompõe (Pereira, 1990; Landers, 1995). Por essa razão, resíduos com maior relação $\mathrm{C} / \mathrm{N}$ (carbono/nitrogênio), como os de plantas de cobertura, podem ser utilizados para aumentar a disponibilidade de palha para o plantio direto, pois quanto maior essa relação, mais lenta será a sua decomposição (Calegari et al., 1993).

As espécies do gênero Urochloa destacam-se pela excelente adaptação a solos de baixa fertilidade, fácil estabelecimento e considerável produção de fitomassa (Timossi et al., 2007). Além disso, essas espécies são forrageiras difundidas e aceitas pelos produtores rurais (Bernardes, 2003), o que facilita a sua adoção em sistemas de integração lavoura-pecuária (Macedo,

Pesq. agropec. bras., Brasília, v.46, n.10, p.1241-1246, out. 2011 
2001). Nesses sistemas, o emprego de espécies forrageiras torna possível a produção de pasto para os animais e de palha para o plantio direto. Aidar et al. (2000) verificaram que o consórcio entre Urochloa e milho produziu $17 \mathrm{Mg} \mathrm{ha}^{-1}$ de matéria seca e que, três meses após a dessecação, $9 \mathrm{Mg} \mathrm{ha}^{-1}$ permaneceram sobre o solo.

O processo de dessecação das plantas de cobertura é uma prática indispensável para a implantação do plantio direto. No caso da braquiária, a dose a ser empregada varia de acordo com a espécie e o estádio de desenvolvimento das plantas (Timossi et al., 2006; Franco et al., 2010). Portanto, o estudo da suscetibilidade diferencial a herbicidas, por espécies de cobertura do solo, tem importância econômica e é relevante para o desenvolvimento de tecnologias sustentáveis de aplicação de defensivos.

O objetivo deste trabalho foi avaliar a suscetibilidade diferencial de espécies de Urochloa ao herbicida glifosato.

\section{Material e Métodos}

Dois experimentos foram implantados na Embrapa

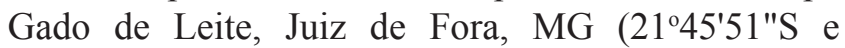
$\left.43^{\circ} 21^{\prime} 01^{\prime \prime W}\right)$. O primeiro deles foi desenvolvido em vasos, dispostos em bancadas em ambiente aberto. Utilizou-se o delineamento em blocos ao acaso, em parcelas subdivididas, com quatro repetições. Nas parcelas, foram testadas três espécies de Urochloa - U. brizantha cv. Marandu, U. decumbens cv. Basilisk e $U$. ruziziensis cv. Comum - e, nas subparcelas, foram dispostas as doses do equivalente ácido (e.a.) do herbicida glifosato (Trop): 0, 180, 360, $540,720,1.080$ e $1.440 \mathrm{~g} \mathrm{ha}^{-1}$.

As sementes das três espécies de Urochloa foram colocadas para germinar em caixas de plástico com substrato comercial, e as plântulas foram transplantadas com 3-4 folhas em 28/11/2007, para bandejas com tubetes $\left(30 \mathrm{~cm}^{3}\right)$ preenchidos com o mesmo substrato. Aproximadamente 40 dias após o transplantio, três plantas foram transferidas para vasos de $5 \mathrm{~L}$ de capacidade, com substrato à base de terra, areia e esterco (1:1:1). Os vasos foram irrigados uma vez por dia com $200 \mathrm{~mL}$ de água. Foram realizados dois cortes de uniformização nas plantas e, cerca de 45 dias após o último corte, foi realizada a aplicação dos tratamentos. As doses do glifosato foram aplicadas em 18/4/2008, tendo-se utilizado um pulverizador experimental, mantido à pressão constante por $\mathrm{CO}_{2}$, equivalente a $2 \mathrm{kgf} \mathrm{cm}^{-2}$. A barra de pulverização (Herbicat Ltda., Catanduva, SP, Brasil) tinha 1,0 $\mathrm{m}$ de largura útil, com dois bicos de jato plano 11002, distanciados em $0,5 \mathrm{~m}$, e volume de pulverização equivalente a $170 \mathrm{~L} \mathrm{ha}^{-1}$. Por ocasião da aplicação, as espécies forrageiras apresentavam altura média de $0,6-0,7 \mathrm{~m}$, no estádio de pré-florescimento. Foi avaliado o percentual de controle das forrageiras aos 10, 18 e 25 dias após a aplicação dos tratamentos (DAA), com o uso de escala de controle de 0 a 100\% (Gazziero et al., 1995).

Após a última avaliação, as plantas foram cortadas para determinação da massa de matéria fresca (MF), e uma amostra foi colocada em estufa com ventilação forçada a $60^{\circ} \mathrm{C}$ por 72 horas, para determinação da percentagem de matéria seca (\%MS). Pela associação dessas duas características, foi estimada a produção de matéria seca (MS).

Todas as características foram submetidas à análise de variância, e as médias foram comparadas pelo teste de Scott-Knott, a 5\% de probabilidade. Foram ajustados modelos lineares de regressão para as doses de glifosato e o percentual de controle aos 10 DAA, e modelos de raiz quadrada para doses de glifosato e a percentagem de matéria seca. A partir dos modelos ajustados para as doses de glifosato e o percentual de controle aos 10 DAA, foram estimados os valores de $\mathrm{C}_{50}$, que representa a dose que proporciona $50 \%$ de controle da espécie.

O segundo experimento foi desenvolvido no Campo Experimental de Coronel Pacheco, Município de

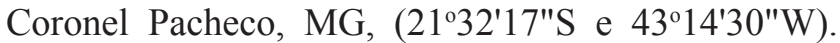
Utilizou-se o delineamento em blocos ao acaso, com parcelas subdivididas, com três repetições. Nas parcelas, foram semeadas as três espécies de Urochloa - U. brizantha [valor cultural (VC) de 34,4\%], U. decumbens (VC de 32\%) e U. ruziziensis (VC de 80\%) - e, nas subparcelas, foram aplicadas doses do equivalente ácido (e.a.) do herbicida glifosato (Trop): 0, 180, 360, 540, 720, 1.080 e $1.440 \mathrm{~g} \mathrm{ha}^{-1}$.

O experimento foi implantado em 5/12/2008. O solo foi arado e gradeado, e $350 \mathrm{~kg} \mathrm{ha}^{-1}$ do fertilizante NPK (08-28-16) foram distribuídos a lanço e incorporados com grade niveladora. A área das parcelas foi de $63 \mathrm{~m}^{2}$ $(3 \times 21 \mathrm{~m})$, e a das subparcelas de $9 \mathrm{~m}^{2}(3 \times 3 \mathrm{~m})$. Para o plantio, uma quantidade aproximada de $15 \mathrm{~kg} \mathrm{ha}^{-1}$ de sementes das espécies de Urochloa foi semeada em sulcos de $0,03 \mathrm{~m}$ de profundidade, espaçados em 
0,3 m. Cada parcela foi composta por 10 linhas de cada espécie forrageira. As sementes foram cobertas com fina camada de solo e, uma semana após a germinação, foi realizado o raleio, tendo-se mantido aproximadamente 20 plantas por metro linear.

Para o estabelecimento da pastagem, foram realizados dois cortes de uniformização das plantas. A aplicação dos tratamentos foi realizada em 13/5/2009, aproximadamente 160 dias após a semeadura e, aproximadamente, 45 dias após o segundo corte de uniformização. Por ocasião da aplicação dos herbicidas, a braquiária apresentava-se com altura aproximada de 0,6 m, no estádio de pré-florescimento. Para a aplicação do herbicida, foi utilizado um pulverizador experimental, mantido à pressão constante por $\mathrm{CO}_{2}$ equivalente a $2 \mathrm{kgf} \mathrm{cm}^{-2}$. Foi utilizada uma barra de pulverização (Herbicat Ltda., Catanduva, SP, Brasil) com largura útil de $3,0 \mathrm{~m}$, com seis bicos de jato plano 110015, distanciados em 0,5 m entre si, e volume de pulverização equivalente a $150 \mathrm{~L} \mathrm{ha}^{-1}$. Avaliou-se, visualmente, o percentual de controle das espécies aos 21 DAA, tendo sido utilizada a mesma escala percentual de controle do primeiro experimento. Nessa mesma data, avaliou-se o teor de clorofila, por meio do determinador de clorofila SPAD-502 Konica Minolta (Spectrum Technology Inc., Plainfield, Illinois, EUA). Além disso, foram determinadas a produção de matéria fresca (MF) e a percentagem de matéria seca (\%MS), conforme descrito no primeiro experimento.

Os dados foram submetidos à análise de variância, e as médias comparadas pelo teste de Scott Knott, a $5 \%$ de probabilidade. Foram ajustados modelos lineares de regressão para as doses de glifosato e o percentual de controle, aos 21 DAA, e para as doses de glifosato e o teor de clorofila. Também foram ajustados modelos de raiz quadrada para doses de glifosato e a percentagem de matéria seca. A partir dos modelos ajustados para as doses de glifosato e o percentual de controle aos 21 DAA, foram estimados os valores de $\mathrm{C}_{50}$. Determinou-se, também a correlação de Spearman entre as médias da percentagem de controle aos 21 DAA e do teor de clorofila (Cruz et al., 2004).

As médias mensais de temperatura do ar e do total de precipitação pluvial, ocorridas durante o período experimental, encontram-se na Tabela 1 .

\section{Resultados e Discussão}

A análise de variância do primeiro experimento evidenciou a existência de efeitos das doses do herbicida e das espécies de Urochloa, para todas as variáveis consideradas. As interações entre esses fatores, de modo geral, também foram significativas, o que indica que o comportamento das espécies não é consistente com a alteração nas doses de glifosato.

Observou-se que as médias de dano às plantas de U. ruziziensis, nas duas primeiras avaliações visuais (10 e 18 DAA), foram maiores do que as observadas para $U$. decumbens e $U$. brizantha (Tabela 2), o que confirma a hipótese de que $U$. ruziziensis é mais suscetível ao glifosato. As diferenças entre as espécies diminuíram com o decorrer das avaliações até se igualarem, aos 25 dias após a aplicação. Na primeira avaliação, aos 10 dias após a aplicação do dessecante,

Tabela 1. Médias mensais de temperatura do ar e precipitação pluvial ocorridas durante a condução do primeiro (Nov./2007 a Maio/2008) e do segundo (Dez./2008 a Jun./2009) experimentos.

\begin{tabular}{|c|c|c|c|c|c|c|c|c|c|c|c|c|c|c|}
\hline \multirow[t]{3}{*}{ Variável } & \multicolumn{7}{|c|}{ Primeiro experimento } & \multicolumn{7}{|c|}{ Segundo experimento } \\
\hline & \multicolumn{2}{|c|}{2007} & \multicolumn{5}{|c|}{2008} & 2008 & \multicolumn{6}{|c|}{2009} \\
\hline & Nov. & Dez. & Jan. & Fev. & Mar. & Abr. & Maio & Dez. & Jan. & Fev. & Mar. & Abr. & Maio & Jun. \\
\hline Temperatura $\left({ }^{\circ} \mathrm{C}\right)$ & 22,6 & 23,9 & 24,0 & 23,9 & 23,3 & 22,6 & 19,1 & 22,8 & 24,3 & 23,2 & 25,5 & 22,0 & 19,2 & 17,2 \\
\hline Precipitação (mm) & 147,0 & 292,3 & 177,3 & 273,6 & 475,3 & 135,0 & 85,3 & 529,5 & 278,7 & 105,1 & 179,2 & 35,1 & 31,8 & 37,6 \\
\hline
\end{tabular}

Tabela 2. Percentagem de controle aos 10, 18 e 25 dias após a aplicação (DAA) de glifosato, massa de matéria fresca (MF) e seca (MS) e percentagem de matéria seca da forragem de três espécies de braquiária, submetidas à aplicação de diferentes doses de glifosato, no experimento em vasos ${ }^{(1)}$.

\begin{tabular}{|c|c|c|c|c|c|c|}
\hline \multirow[t]{2}{*}{ Espécie } & \multicolumn{3}{|c|}{ Controle $(\%)$} & $\mathrm{MF}$ & MS & \multirow{2}{*}{$\begin{array}{l}\text { MS } \\
(\%)\end{array}$} \\
\hline & $10 \mathrm{DAA}$ & 18 DAA & $25 \mathrm{DAA}$ & \multicolumn{2}{|c|}{--------- (g por vaso) --------- } & \\
\hline Urochloa brizantha & $62,31 \mathrm{c}$ & $76,26 \mathrm{c}$ & $84,8 \mathrm{a}$ & $118,0 \mathrm{a}$ & $51,8 \mathrm{a}$ & $47,68 \mathrm{c}$ \\
\hline Urochloa decumbens & $70,50 \mathrm{~b}$ & $82,38 b$ & $84,9 \mathrm{a}$ & $97,14 b$ & $49,9 \mathrm{a}$ & $57,50 \mathrm{a}$ \\
\hline Urochloa ruziziensis & $78,38 \mathrm{a}$ & $84,83 a$ & $84,8 \mathrm{a}$ & $95,01 b$ & $45,7 \mathrm{a}$ & $54,88 b$ \\
\hline
\end{tabular}

${ }^{(1)}$ Médias seguidas de letras iguais, nas colunas, não diferem pelo teste de Scott-Knott, a 5\% de probabilidade. 
os danos causados às plantas de $U$. ruziziensis foram aproximadamente $20 \%$ maiores do que os ocorridos em $U$. brizantha, que foi o material que apresentou os menores danos. Esses resultados indicam que é possível plantar com menor intervalo entre a dessecação e a semeadura, quando U. ruziziensis é a principal cobertura vegetal da área. Rizzardi et al. (2003) relatam que a capacidade competitiva da cultura da soja, em relação às plantas daninhas, é aumentada quando a semeadura é realizada mais próxima à data da dessecação. Todavia, se a área a ser utilizada para o plantio direto tem grande quantidade de cobertura vegetal, a dessecação deve ser feita no mínimo 15 a 25 dias antes da semeadura da cultura, a fim de evitar possíveis danos à produtividade (Constantin et al., 2007, 2009).

As avaliações realizadas aos 25 dias após a aplicação do produto não contribuíram para a separação das doses e das espécies, uma vez que todas as plantas apresentaram sintomas semelhantes em qualquer uma das doses testadas (Tabela 2), à exceção do tratamento testemunha (dose zero). Portanto, futuros trabalhos, realizados em condições semelhantes, devem priorizar avaliações dos danos às plantas em intervalos mais próximos à aplicação dos tratamentos.

$\mathrm{Na}$ avaliação das médias de produtividade de forragem das diferentes espécies estudadas, observouse maior produção de matéria fresca em $U$. brizantha e ausência de diferenças entre as médias de produção de matéria seca (Tabela 2). A maior produtividade de forragem observada em $U$. brizantha, em comparação principalmente a U. ruziziensis, corrobora os resultados da literatura e evidencia o maior potencial produtivo de $U$. brizantha, especialmente em avaliações realizadas no outono/inverno (Souza Sobrinho, 2005; Souza, 2007; Souza Sobrinho et al., 2009). O maior valor da percentagem média de matéria seca da forragem produzida (\%MS) foi obtido em $U$. decumbens, seguida por $U$. ruziziensis e $U$. brizantha.

Quanto aos danos causados às plantas pelo dessecante, a avaliação aos 10 DAA foi a que detectou maiores diferenças entre as espécies (Figura 1 A). Urochloa ruziziensis foi a espécie mais suscetível ao glifosato, enquanto os valores para $U$. decumbens foram intermediários. Urochloa ruziziensis apresentou valor de $\mathrm{C}_{50}$ de 646,5 $\mathrm{g} \mathrm{ha}^{-1}$ de e.a., enquanto $U$. decumbens e $U$. brizantha apresentaram valores de 675,3 e 769,0 g ha $^{-1}$ de e.a., respectivamente. Essa diferença representa redução de 12 a $16 \%$ na quantidade de herbicida a ser aplicada, para que se obtenha um mesmo controle das espécies. Esse resultado é relevante em termos econômicos e contribui para viabilizar o uso sustentável de herbicidas.

Urochloa brizantha foi a espécie com menor percentagem de matéria seca (Figura $1 \mathrm{~B}$ ), enquanto $U$. decumbens e $U$. ruziziensis apresentaram comportamento semelhante, à medida que houve aumento das doses do herbicida.

No segundo experimento também foram verificadas diferenças significativas entre as espécies (Tabela 3). Isto está de acordo com os resultados observados no primeiro experimento.

Quanto ao percentual de controle aos 21 dias após a aplicação das doses do glifosato, U. ruziziensis foi a espécie mais suscetível ao herbicida, tendo apresentado
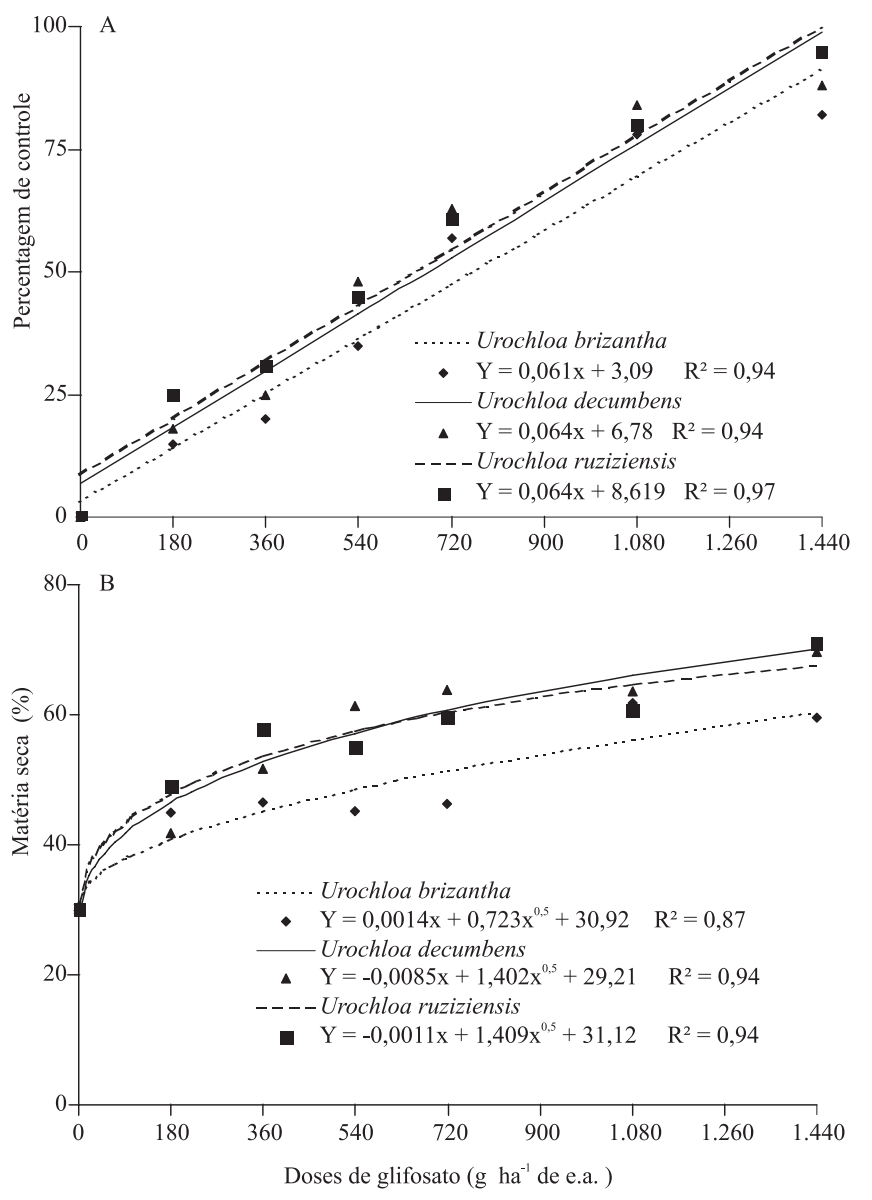

Figura 1. Percentual de controle de espécies de braquiária, aos dez dias após a aplicação dos tratamentos (A) e percentagem de matéria seca (B), em função da aplicação das doses de equivalente ácido do herbicida glifosato, no experimento em vasos. 
percentagem de controle de $68,8 \%$, aproximadamente $37 \%$ superior aos valores observados em $U$. brizantha e $U$. decumbens que não diferiram significativamente pelo teste de Scott-Knott (Tabela 3).

Resultados semelhantes foram observados nas medições do teor de clorofila nas folhas, após a aplicação das doses do herbicida. No entanto, as espécies foram separadas em três grupos distintos (Tabela 3), o que não havia acontecido com a avaliação visual do percentual de controle. Urochloa ruziziensis permaneceu como a espécie mais suscetível ao herbicida. A boa associação entre as duas formas de avaliação dos danos causados às plantas pelo herbicida é confirmada pela correlação significativa, negativa e alta $(r=-0,947)$, obtida entre o percentual de controle aos 21 DAA e o teor de clorofila. Esses resultados eram esperados, pois o glifosato inibe a síntese de aminoácidos (triptofano, tirosina e fenilalanina) e, à medida que os sintomas se agravam, observa-se o amarelecimento progressivo das folhas, seguido de necrose dos tecidos (Rodrigues \& Almeida, 2005).

A avaliação visual de controle é um método subjetivo e muito influenciado pela experiência dos avaliadores. Embora mundialmente aceito para avaliação e análise de experimentos com herbicidas, métodos complementares e de maior acurácia, como a avaliação do teor de clorofila, devem ser utilizados na confirmação e auxílio na análise e interpretação dos resultados.

$\mathrm{O}$ valor de $\mathrm{C}_{50}$, observado para $U$. ruziziensis, foi de $637,7 \mathrm{~g} \mathrm{ha}^{-1}$ de e.a, enquanto $U$. decumbens e $U$. brizantha apresentaram valores de 717,3 e 755,6 g ha $^{-1}$ de e.a., respectivamente (Figura 2 A). Urochloa ruziziensis foi a espécie com maior percentagem de matéria seca (Figura $2 \mathrm{~B}$ ), enquanto que $U$. decumbens e U. brizantha apresentaram comportamentos

Tabela 3. Percentagem de controle aos 21 dias após a aplicação (DAA) de glifosato, teor de clorofila nas plantas, massa de matéria fresca (MF) e percentagem de matéria seca (MS) da forragem de três espécies de braquiária, submetidas à aplicação de diferentes doses do herbicida, no experimento em campo ${ }^{(1)}$.

\begin{tabular}{lcccc}
\hline Espécies & $\begin{array}{c}\text { Controle aos } \\
\text { 21 DAA (\%) }\end{array}$ & $\begin{array}{c}\text { Teor de clorofila } \\
\text { (Índice SPAD) }\end{array}$ & $\begin{array}{c}\text { MF } \\
\left(\mathrm{g} \mathrm{m}^{-2}\right)\end{array}$ & $\begin{array}{c}\text { MS } \\
(\%)\end{array}$ \\
\hline Urochloa brizantha & $42,3 \mathrm{~b}$ & $28,3 \mathrm{~b}$ & $1.941,2 \mathrm{a}$ & $54,1 \mathrm{~b}$ \\
Urochloa decumbens & $43,8 \mathrm{~b}$ & $31,2 \mathrm{c}$ & $2.123,28 \mathrm{a}$ & $53,6 \mathrm{~b}$ \\
Urochloa ruziziensis & $68,8 \mathrm{a}$ & $19,5 \mathrm{a}$ & $1.031,2 \mathrm{~b}$ & $70,1 \mathrm{a}$ \\
\hline (1) Médias seguidas de letras iguais, nas colunas, não diferem pelo teste de \\
Scott-Knott, a 5\% de probabilidade.
\end{tabular}

semelhantes à medida que houve aumento das doses aplicadas do herbicida. Quanto ao teor de clorofila, U. ruziziensis foi a espécie que apresentou os menores valores (Figura $2 \mathrm{C}$ ), o que confirma os resultados das avaliações de controle.
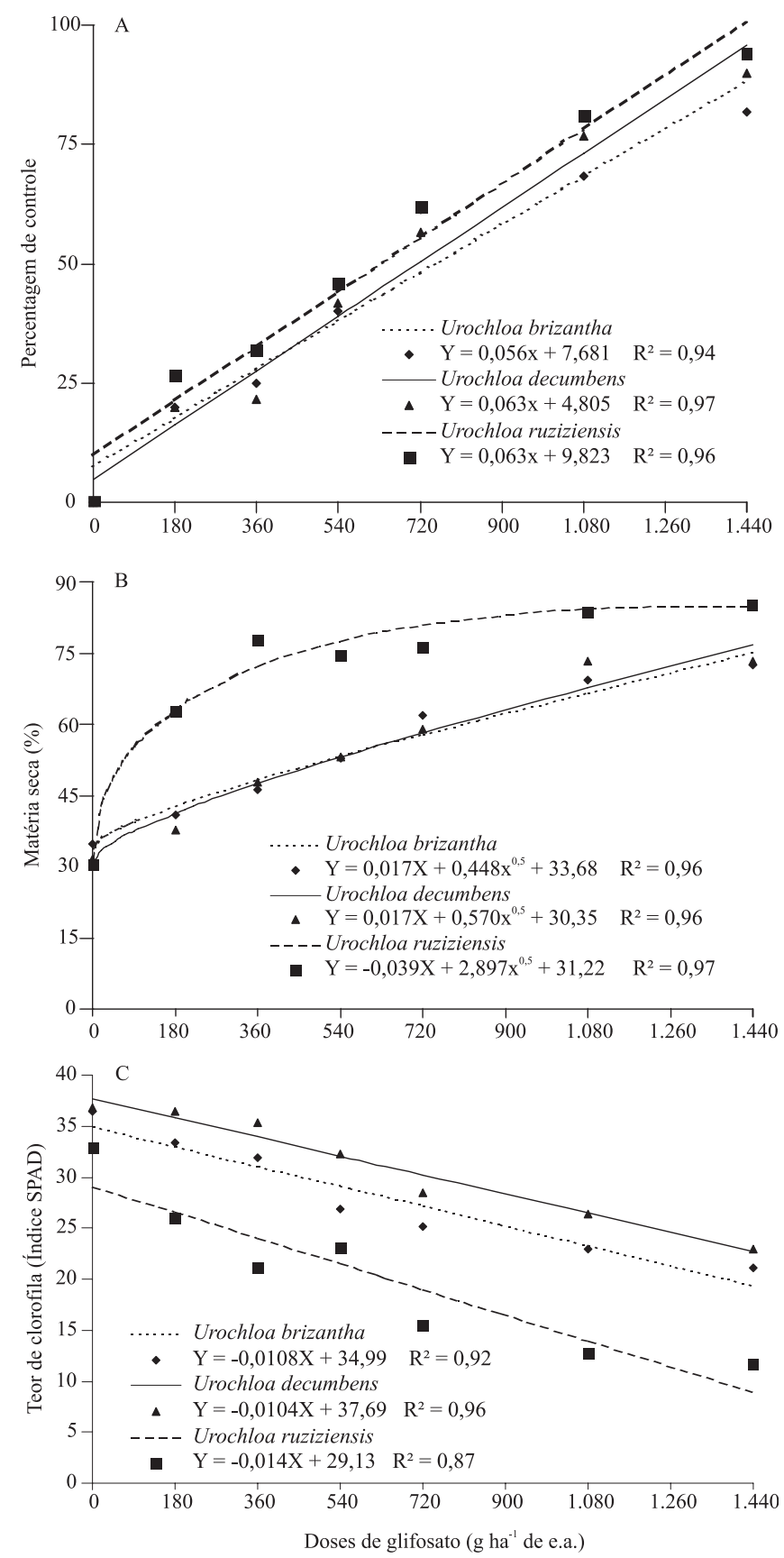

Figura 2. Percentual de controle de espécies de braquiária, aos 21 dias após a aplicação dos tratamentos (A), percentagem de matéria seca (B) e teor de clorofila (C), em função da aplicação das doses de equivalente ácido do herbicida glifosato, no experimento em campo. 


\section{Conclusões}

1. Há diferença de suscetibilidade ao herbicida glifosato entre as espécies de Urochloa, e U. ruziziensis é a espécie mais suscetível.

2. O conhecimento da suscetibilidade diferencial entre as espécies de Urochloa avaliadas permite uma economia de 12 a 16\% na dose do herbicida glifosato.

\section{Agradecimentos}

À Fundação de Amparo à Pesquisa do Estado de Minas Gerais e ao Conselho Nacional de Desenvolvimento Científico e Tecnológico, pelo apoio financeiro.

\section{Referências}

AIDAR, H.; THUNG, M.; OLIVEIRA, I.P.; KLUTHCOUSKI, J.; CARNEIRO, G.E.S.; SILVA, J.G. da; DEL PELOSO, M.J. Bean production and white mould incidence under no-till system. Annual Report of the Bean Improvement Cooperative, v.43, p.150-151, 2000.

BERNARDES, L.F. Semeadura de capim-braquiária em pós-emergência da cultura do milho para obtenção de cobertura morta em sistema de plantio direto. 2003. 42p. Dissertação (Mestrado) - Universidade Estadual Paulista, Jaboticabal.

CALEGARI, A.; MONDARDO, A.; BULISANI, E.A.; COSTA, M.B.B. da; MIYASAKA, S.; AMADO, T.J.C. Aspectos gerais da adubação verde. In: COSTA, M.B.B. da (Coord.). Adubação verde no Sul do Brasil. 2.ed. Rio de Janeiro: Assessoria e Serviços a Projetos em Agricultura Alternativa, 1993. p.1-56.

CONSTANTIN, J.; OLIVEIRA JÚNIOR, R.S. de; CAVALIERI, S.D.; ARANTES, J.G.Z.; ALONSO, D.G.; ROSO, A.C.; COSTA, J.M. Interação entre sistemas de manejo e de controle de plantas daninhas em pós-emergência afetando o desenvolvimento e a produtividade do milho. Planta Daninha, v.25, p.513-520, 2007.

CONSTANTIN, J.; OLIVEIRA JÚNIOR, R.S. de; INOUE, M.H.; ARANTES, J.G.Z. de; CAVALIERI, S.D. Sistemas de dessecação antecedendo a semeadura direta de milho e controle de plantas daninhas. Ciência Rural, v.39, p.971-976, 2009.

CRUZ, C.D.; REGAZZI, A.J.; CARNEIRO, P.C.S. Modelos biométricos aplicados ao melhoramento genético. 3.ed. Viçosa: UFV, 2004. 480p.

FRANCO, C.F.; FREITAS, T.T.; TIMOSSI, P.C.; GONÇALVES, R.N.; BARRETO, V.C.M. Racionalização no uso de glyphosate com a adoção de brachiaria como planta de cobertura. In: CONGRESSO BRASILEIRO DA CIÊNCIA DAS PLANTAS
DANINHAS, 27., 2010, Ribeirão Preto. Responsabilidade social e ambiental no manejo de plantas daninhas: anais. Ribeirão Preto: SBCPD, 2010. p.591-595.

GAZZIERO, D.L.P.; VELINI, E.D.; OSIPE, R. Procedimentos para instalação, avaliação e análise de experimentos com herbicidas. Londrina: Sociedade Brasileira da Ciência de Plantas Daninhas, 1995. 42p.

LANDERS, J.N. Fascículo de experiências de plantio direto no Cerrado. Brasília: Associação de Plantio Direto no Cerrado, 1995. $261 \mathrm{p}$.

MACEDO, M.C.M. Integração lavoura e pecuária: alternativa para a sustentabilidade da produção animal. In: SIMPÓSIO SOBRE MANEJO DA PASTAGEM, 18., 2001. Piracicaba. Planejamento de sistemas de produção em pastagens: anais. Piracicaba: FEALQ, 2001. p.257-283.

PEREIRA, F.A.R. Cultivo de espécies visando a obtenção de cobertura vegetal do solo na entressafra da soja (Glycine $\max$ L. Merrill) no Cerrado. 1990. 83p. Dissertação (Mestrado) Universidade Estadual Paulista, Botucatu.

RIZZARDI, M.A.; FLECK, N.G.; RIBOLDI, J.; AGOSTINETTO, D. Ajuste de modelo para quantificar o efeito de plantas daninhas e a época de semeadura no rendimento de soja. Pesquisa Agropecuária Brasileira, v.38, p.35-43, 2003.

RODRIGUES, B.N.; ALMEIDA, F.S. de. Guia de herbicidas. 5.ed. Londrina: [s.n.], 2005. 591p.

RUEDELL, J. Plantio direto na região de Cruz Alta. Cruz Alta: Fundacep; Fecotrigo, 1995. 134p.

SOUZA SOBRINHO, F. de. Melhoramento de forrageiras no Brasil. In: EVANGELISTA, A.R.; AMARAL, P.N.C. do; PADOVANI, R.F.; TAVARES, V.B.; SALVADOR F.M.; PERÓN, A.J. (Ed.) Forragicultura e pastagens: temas em evidência. Lavras: UFLA, 2005. p.65-120.

SOUZA SOBRINHO, F. de; LÉDO, F.J. da S.; KOPP, M.M.; PEREIRA, A.V.; SOUZA, F.F. Melhoramento de gramíneas forrageiras na Embrapa Gado de Leite. In: SIMPÓSIO, 7.; CONGRESSO DE FORRAGICULTURA E PASTAGENS, 3., 2009, Lavras. Anais. Lavras: UFLA, 2009. p.98-111.

SOUZA, F.F. Produção e qualidade de forragem de progênies de Brachiaria ruziziensis. 2007. 89p. Dissertação (Mestrado) Universidade Federal de Lavras, Lavras.

TIMOSSI, P.C.; DURIGAN, J.C.; LEITE, G.J. Eficácia de glyphosate em plantas de cobertura. Planta Daninha, v.24, p.475-480, 2006.

TIMOSSI, P.C.; DURIGAN, J.C.; LEITE, G.J. Formação de palhada por braquiárias para adoção do sistema de plantio direto. Bragantia, v.66, p.617-622, 2007

Recebido em 13 de setembro de 2010 e aprovado em 12 de agosto de 2011

Pesq. agropec. bras., Brasília, v.46, n.10, p.1241-1246, out. 2011 